University of New Hampshire

University of New Hampshire Scholars' Repository

\title{
The Relationship between Resilience and Body Image in College Women
}

\author{
Robert J. McGrath \\ University of New Hampshire, robert.mcgrath@unh.edu \\ Wiggin Julie \\ University of New Hampshire - Main Campus \\ Rosemary M. Caron \\ University of New Hampshire - Main Campus
}

Follow this and additional works at: https://scholars.unh.edu/hmp_facpub

Part of the Dietetics and Clinical Nutrition Commons, Health Psychology Commons, and the Women's Health Commons

\section{Recommended Citation}

R McGrath, J Wiggin, R Caron. The Relationship between Resilience and Body Image in College Women. The Internet Journal of Health. 2009 Volume 10 Number 2.

This Article is brought to you for free and open access by the Health Management and Policy at University of New Hampshire Scholars' Repository. It has been accepted for inclusion in Health Management and Policy Scholarship by an authorized administrator of University of New Hampshire Scholars' Repository. For more information, please contact Scholarly.Communication@unh.edu. 


\section{INTERNET SCIENTIFIC PUBLICATIONS}

\section{HOME JOURNALS LATEST ARTICLES DISCLAIMERS ARTICLE SUBMISSIONS}

\section{CONTACT HELP}

The Internet Journal of Health

Volume 10

Number 2

Original Article

\section{The Relationship between Resilience and Body Image in College Women}

R McGrath, J Wiggin, R Caron

\section{Keywords}

body image, resilience, women's health

\section{Citation}

R McGrath, J Wiggin, R Caron. The Relationship between Resilience and Body Image in College Women. The Internet Journal of Health. 2009 Volume 10 Number 2.

\section{Abstract}

Possessing a negative body image is associated with unhealthy eating habits and eating disorders in college women and has been linked to depression and negative feelings of self worth. Limited research exists on protective factors that have the potential to mitigate body image dissatisfaction. This paper examines the relationship of resilience to body image dissatisfaction in college women. Female, undergraduate college students were studied using previously validated measures. Results indicate that increased resilience is associated with improved body image.

\section{Introduction}

Body image is a complex construct that can influence an individual's perceptions about their physical selves (1). Women who hold a negative body image tend to practice unhealthy eating habits which in turn are highly linked to the development of eating disorders especially as they progress through adolescence and into the college environment (2-4). Many young women entering college are challenged with social norms

\section{Author Information}

Robert J. McGrath, PhD

Assistant Professor, College of Health and Human Services, University of New Hampshire

Julie Wiggin, BS

Graduate, College of Health and Human Services, University of New Hampshire

Rosemary M. Caron, PhD, MPH Associate Professor, College of Health and Human Services, University of New Hampshire

\section{Share This Article}

Your free access to ISPUB is funded by the following advertisements: 


\section{Internet Scientific Publications}

associated with overall appearance that have been engrained long before they enter college. As Cooley et al. note, “...the college years may be a particularly appropriate period to study because of the significant life changes and stressors facing late adolescents entering the college environment" (5). These developmental changes have been shown to be significantly linked to increased feelings of figure dissatisfaction among women (5). Research has shown that a number of factors can contribute to body image dissatisfaction. Clinical psychologists and sociocultural theorists have posited that idealized images of attractiveness or beauty can be linked to body image notions (6-8). Others have identified familial and peer relationships (9-14) and referent groups (15) as being influential factors to body image dissatisfaction. However, less empirically explored have been the potential for protective factors that may insulate adolescent women from body image dissatisfaction. Anecdotal evidence has shown that having a referent identity such as feminism may promote resilience in young women, yet the interplay between resilience and body image has not been formally measured or studied. In this article, we hypothesize that college-age women who are more resilient will have a more favorable body image after accounting for the known predictors of body image dissatisfaction found in the literature. Given that college women have been documented to be at risk for many detrimental physical and mental health outcomes, the importance of addressing body image dissatisfaction and identifying positive and protective factors related to its treatment becomes especially salient to college counselors.

\section{Factors Related to Body Image}

\section{Media and Social Comparison}

Having a negative body image has been linked to a number of social, psychosocial, and environmental factors. One factor commonly perceived to be of influence to young women is media and social comparison. Developed by Leon Festiger, social comparison theory suggests that comparison to a larger reference group motivates the individual, in this case young women, towards uniformity (16). Renee Engeln-Maddox studied this effect in college women, where she found that comparing one's self to media images was associated with "body dissatisfaction, thin-ideal endorsement, and a drive for thinness" (8). These results supported previous research findings by Stormer and Thompson and also Taylor et al. $(16,17)$. Such negative media effects continue to be pervasive in modern western society. As Hoyt surmises, "In the past 30 years, the average body size of Miss America winners has decreased significantly $(2,18,19)$, the prevalence of diet and exercise articles in women's magazines has grown exponentially (18-21), and the physical appearance of the average fashion model is now achievable by only $3-5 \%$ of the U.S. population" (21).

\section{Peer and Familial Relationships}

A second set of contributing factors to body image dissatisfaction revolve around peer and familial relationships. The input received in a family environment and during the formative years can both positively and negatively influence a woman's perception of self image. In a longitudinal study, Hesse-Biber et al. found that having a positive role model in the home can lead to improved body image, and that women who reported teasing and hypercritical family members were more likely to experience disordered eating (22). This time in young women's lives is crucial to the development of a positive body image. If at this point, development of a negative body image takes place, it can be detrimental to future self-perceptions and can greatly influence future eating and exercise behaviors once in the college environment. Additionally, influential to body image perceptions are women's relationships with peer and referent groups. These influences are particularly important for adolescent women as relationships expand to include emotional and sexual 


\section{Internet Scientific Publications}

ones, especially during the college years. The existence and desire for partner relations has been found to be directly correlated to perceptions of body image. Women also realize these pressures more than men do since men have been shown to emphasize physical attraction to a greater degree than do women when choosing a partner (2, 10-14, 23). Townsend and Levy found that men are less likely to engage in a relationship with women they find unattractive (14). This hypothesis is supported by Forbes et al., who surveyed young college women and found that having a boyfriend is associated with having a more favorable body image (24).

The results of Hoyt et al.'s study examining peer relationships and body image are also interesting in terms of the connection between peer relationships and body image. Along with the result that women are significantly more dissatisfied with their weight than men (a common result), the authors found that "women who were underweight were the most dissatisfied with their relationships with peers of the same gender. Therefore, not only does being thinner not make these women happier, it is actually linked to less satisfying relationships with other women" (2). Those who perceive themselves as being overweight want to be thinner because they believe this makes them more sexually attractive and this is associated with finding someone interested in pursuing a relationship. However, those who achieve thinness, or are already thin, complain about strained relationships with other women because of social competition. Other psycho-social factors that have been related to body image dissatisfaction in women, including depression, gender roles, and vulnerability. In a review of these factors, Hyde, Mezulis and Abramson posit that these are complex factors that are interrelated and linked within the broader context of the pubertal process and pubertal timing (25).

\section{Resilience and Body Image Dissatisfaction}

One of the first studies to relate the idea of resilience and body image dissatisfaction is one conducted by Rubin et al. in which the authors examine college women through the use of focus group discussions to identify how the feminist attitude not only helps to ward off societal pressures but intervenes in the process of body dissatisfaction and allows women to maintain positive body images. Although the study finds that feminist beliefs do not necessarily hinder feelings about body image, lower levels of body dissatisfaction are found to be associated with feminism. In the study, the authors indicate that they are "particularly interested in examining risk, resiliency, and resistance among feminist women to understand how feminists attempt to maintain positive feelings about their bodies while living in a culture that objectifies female bodies and links women's economic and social power to their appearance" (26). Resiliency as a measurable factor, however, was not specifically examined in this study.

The term resilience has been used widely and with varied definition. Here, we define the term in accordance with Wagnild et al., as the ability to successfully cope with change or misfortune. Wagnild and Young originally conducted a study of resilience in order to validate the use of the resiliency scale. To date, the resiliency scale has been used in numerous studies including those examining resiliency in young women and is one of the most utilized resiliency testing tools (http://www.resiliencescale.com/references.htm). A 2006 review of scales for measuring resilience found that the Wagnild and Young scale was the most appropriate to use for studying adolescents (27).

While resilience has been examined across a number of health related domains, there has been no empirical study to date examining the effect of resiliency on body image dissatisfaction in young women. In 2007, Choate proposed a resiliency model to counter body image dissatisfaction in young adolescent women that focused on the domains of media influence and familial and peer relationships and is promoted as a targeted 


\section{Internet Scientific Publications}

intervention for school counselors, however it was not based on any previous empirical links between the two $(28,29)$.

Here, we hypothesize that resiliency may have a measurable mitigating effect on body image dissatisfaction in young women. Specifically, we hypothesize that as a young woman's resilience increases, her body image dissatisfaction will decrease.

\section{Methods}

\section{Participants and Procedure}

The study population was comprised of 177 female college students enrolled at medium sized northeast university. Female students aged 18 to 22 years old voluntarily participated in the anonymous study.

The university's institutional review board approved this study. Participants were recruited through undergraduate general education classes known to have large enrollment. This is a form of judgment sampling, in which the researcher identifies a sample from a known sampling frame that is most able to answer the research question (27).

Permission was granted by class professors to use the first ten minutes of class time to distribute and collect surveys. This approach allowed for a 100 percent return rate. Included were courses in Anthropology, Microbiology, Math, Epidemiology, and The History of Public Health. Surveys were administered over a period of eight weeks in the spring of 2007.

All of the surveys were prefaced with information about the study, confidentially and anonymity rights, as well as the student's right to refuse participation. There were no incentives for participating in this study.

The questionnaire consisted of 29 items including two scales, one which measured body image dissatisfaction and the other resiliency. Demographic questions included age, height, weight, grade-level, living situation, roommate situation, parental relationship status, number of siblings and perceived relationship with parents. Grade level asked which class the student identified with, freshman, sophomore, junior, or senior. Living situation asked the sex and number of roommates the respondent had. Questions about grade-level, living situation and roommate situation were included to examine the nature of peer relations and social comparison. Home and parental relationships were examined through questions asking about the number of siblings, perceived parental relationships, and parental relationship status. Questions about depression and vulnerability were not included given that they have been shown to be complexly interrelated, and thus may be correlated with the construct of resilience.

\section{Measures}

\section{Body Image}

Respondents answered three questions following the examination of a body satisfaction silhouette scale. This scale was developed and validated by Cooley and Toray (30). Such scales have been found to be reliable and cost effective for the study of body image perceptions, as well as analytically preferable as it allows ordinal data to be interpreted as interval data allowing for inference determinations (15, 31). Respondents were shown eleven silhouettes of women ranging in size from smallest to largest. Each image was numbered, as was a blank space between each. Respondents were then asked to identify the silhouette that best resembled the way they thought they looked, would ideally 


\section{Internet Scientific Publications}

like to look and the one they believed men would find most attractive. Respondents circled the number that corresponded to these placements on the scale. The beginning and thinnest silhouette was numbered 1 and the last and largest 21. Image dissatisfaction was calculated as the distance in whole numbers from the number circled beneath what the respondent believed best represented the way they looked subtracted from that beneath the ideal image and then again for the image they felt men would be attracted to. For example, if a woman reported their perceived image silhouette number as 21 , and their ideal image silhouette image as number 15, their score would be 6, or 21 minus 15 . The same was done for how they scored the image they believed men would find attractive subtracted from that corresponding to their perceived true body image. A greater difference between actual and ideal in either direction indicated greater body image dissatisfaction. This results in a single numerical measure of body image dissatisfaction. Validation of the scale's measurement was originally determined by Cooley by calculating the Body Mass Index (BMI) for respondents and performing a correlation between the corresponding number for the figure chosen as closest to self with the individual's BMI. They reported a correlation of $r=.79(p<.001)$, which suggested a close correspondence between the chosen silhouette and the individual's BMI (30). This procedure was repeated for this study where the correlation was supported at $r=.674,(p<.001)$.

\section{Resiliency}

The remaining 15 survey questions comprised the resiliency scale developed by Gail M. Wagnild et al. (32). Validity of the scale was determined through a factor analysis with a reported coefficient of .91 (32). Scale questions utilized a 7-point Likert scale with 1 representing "I strongly disagree" and 7 representing "I strongly agree". Examples of questions are: "When I make plans I follow through with them," "I feel proud that I have accomplished things in my life," "I have self-discipline," and "When I am in a difficult situation, I can usually find my way out of it." Resiliency scores were calculated by summing the responses across the 15 questions. Respondents could score between a minimum of 15 to a maximum of 105 on the scale. A higher score equated to a higher level of resiliency.

\section{Analysis}

Collected data were analyzed using the Statistical Package for Social Sciences (SPSS), Version15.0. Descriptive analyses were conducted for the variables of age, grade level, current residence of the respondent, number of siblings, relationship status of the respondent's parents and the perceived relationship the respondent had with parents, silhouette score of self, ideal silhouette score, silhouette score as perceived by men, resiliency, and $\mathrm{BMI}$.

The primary variables of resilience and silhouette scores were then calculated. The absolute value of the silhouette score difference was taken to measure the total distance between the ideal and perceived silhouette scores.

Bivariate analysis tested the primary variables of body image score and resilience against the factors of number of roommates, sex of roommates, living situation, perceived parental relationship and relationship status of the respondent's parents through the use of t-tests. Body image difference scores were calculated for both the ideal image compared to the perceived real, and also the male ideal compared to the perceived real. A correlation between the two was then calculated.

To examine the effect of resiliency on body image satisfaction, a multiple regression model was constructed. Using a forward stepwise method, the model was refined. Non- 


\section{Internet Scientific Publications}

significant and/or intolerant predictor variables were dropped and the model re-examined using the R-square determinant of explanatory power and the F-test of model fit. A correlation matrix was conducted to examine collinearity of the predictor variables. Normality of interval level data was determined and multicollinearity was examined for all IVs included and excluded from the model at a tolerance of $>$.1. Normality of the predictor and dependent variables were examined using predicted residuals plots and were determined to be normally distributed.

\section{Results}

The nature of the in-class survey distribution allowed for a 100 percent return rate. 177 surveys were completed and returned. Of those, 171 had complete answers to all questions.

Tables 1 and 2 summarize the descriptive responses. The mean age of the respondents was $19(\mathrm{SD}=1.705,95 \% \mathrm{Cl}=19.45-20.00)$. Student breakdown by class was comparable to the university overall for the sophomore, junior and senior classes. Freshmen were over represented. This is likely because freshmen are more inclined to enroll in general education classes than other students. This did not skew results as examination of mean dependent variable scores by class revealed no significant differences.

\section{Figure 1}

Table 1: Descriptive analyses continuous variables

\begin{tabular}{|l|c|c|c|c|c|}
\hline & $\mathrm{N}$ & Minimum & Maximum & Mean & $\begin{array}{c}\text { Std. } \\
\text { Deviation }\end{array}$ \\
\hline Age at last birthday & 174 & 17 & 34 & 19.75 & 1.70 \\
\hline Number of & 171 & 1 & 6 & 2.57 & 1.74 \\
Roommates & 176 & 1 & 6 & 2.83 & 1.10 \\
\hline Number of children & & & & & \\
in your family. & 174 & 95 & 200 & 135.14 & 19.48 \\
\hline $\begin{array}{l}\text { Current Weight } \\
\text { Resiliency }\end{array}$ & 174 & 52 & 105 & 87.96 & 9.99 \\
\hline
\end{tabular}

\section{Figure 2}

Table 2: Descriptive analyses categorical variables 


\section{Internet Scientific Publications}

\begin{tabular}{|c|c|c|c|c|}
\hline Variable & $\%$ & Variable & & $\%$ \\
\hline Grade Level & & $\begin{array}{l}\text { Gender of } \\
\text { Roommates }\end{array}$ & & \\
\hline Freshman & 37.3 & & Female & 92.4 \\
\hline Sophomore & 20.3 & & Male or $\mathrm{C}_{0}$-ed & 7.6 \\
\hline Junior & 22.0 & & & \\
\hline Senior & 20.3 & Number of $\mathrm{P}$ & oommates & \\
\hline & & & Zero & 9.4 \\
\hline Living & & & & \\
\hline Location & & & One & 41.5 \\
\hline On Campus & 59.3 & & More than one & 49.1 \\
\hline Off Campus & 40.7 & & & \\
\hline & & Relationship & with Parents & \\
\hline & & & Excellent / Good & 93.1 \\
\hline & & & Average / Poor / Bad & 6.9 \\
\hline
\end{tabular}

\section{Resilience}

Three women failed to complete all the questions and were subsequently dropped from the analysis. The minimum reported resilience score was 52 and the maximum 105 . The mean resiliency score was 87.96 (SD 10.0, 95\% Cl 86.47-89.45). Reported scores closely matched the entire range of potential test scale scores, with just over half of the survey respondents scoring between 88 and 105 points.

\section{Body Image}

The body image satisfaction measure questions were answered by all 177 respondents. As shown in Table 3, the figure selected by women as the one representing how they currently perceive themselves was significantly different from the ideal image they would like to have or the image they believed men would find most attractive. There was no significant difference in the image the women found as ideal as compared to the image they believed men would find most attractive.

\section{Figure 3}

Table 3: Body Image Perceptions 


\begin{tabular}{|l|c|c|c|}
\hline & Mean & SD & $95 \% \mathrm{CI}$ \\
\hline $\begin{array}{l}\text { Which figure is closest } \\
\text { to the way you look? }\end{array}$ & 6.32 & 2.40 & $(5.96-6.67)$ \\
\hline $\begin{array}{l}\text { Which figure is closest } \\
\text { to how you would } \\
\text { ideally like to look? }\end{array}$ & $4.49^{*}$ & 1.35 & $(4.29-4.69)$ \\
\hline $\begin{array}{l}\text { Which figure do you } \\
\text { think men would find } \\
\text { most attractive }\end{array}$ & $4.45^{*}$ & 1.41 & $(4.24-4.66)$ \\
\hline
\end{tabular}

* significan tly different from perceived actual body image $p<.05$

The minimum difference between actual and ideal was 0 and the maximum difference was 10. The mean difference between actual and ideal of all 177 respondents was 1.95 (SD $1.79,95 \% \mathrm{Cl} 1.68-2.21)$. The body image dissatisfaction relative to how respondents felt men would find ideal was similar but slightly more pronounced, with values ranging from 0 to 10 and a mean difference score of 2.40 (SD 1.89, 95\% Cl 2.12-2.68) meaning that they believed themselves to be further from what they perceived men held as an ideal body image than the image that they held for themselves as ideal.

\section{Comparative Analysis}

Bivariate analysis revealed several significant relationships. The first was that there was a significant positive correlation between a women's ideal silhouette and the silhouette that they though men would find most attractive $(r=.543 ; p<000)$. The second was a significant negative correlation between resiliency and body image $(r=-.168, p<.026)$.

We then conducted t-tests for mean differences in resiliency and body image satisfaction scores between the variables number of roommates (one, other than one), roommate gender (male/coed or female), living situation (on/off campus), relationship with parents (good/excellent and average/poor/bad), and relationship of parents (married or other), see Table 3. Only the number of roommates and relationship with parents had significant mean resiliency score differences. There were no significant mean body image score differences by these variables.

\section{Figure 4}

Table 4: Mean Resilience and Body Image Dissatisfaction Comparisons 


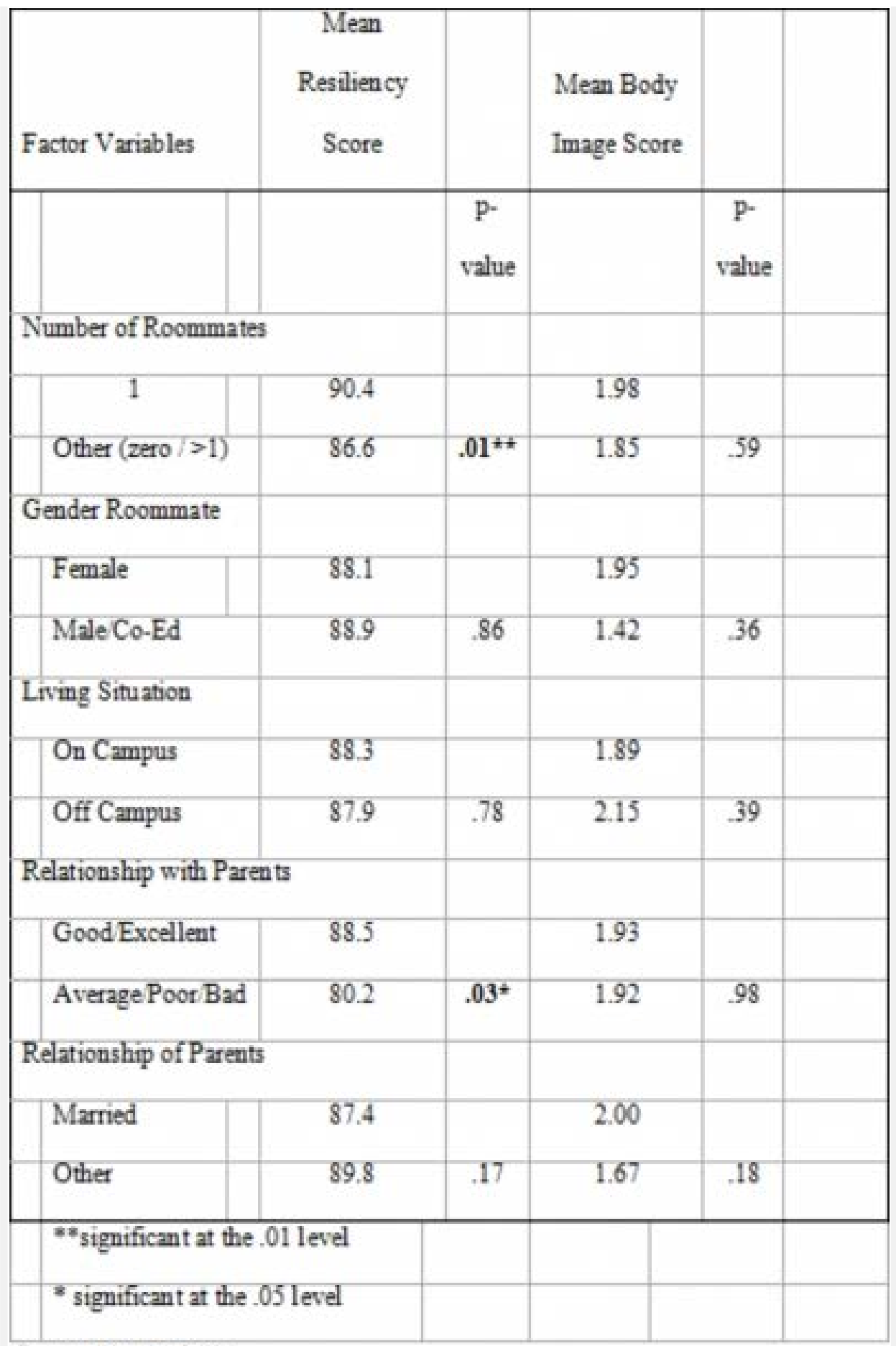

Regression Analysis

Prior to running the regression analysis, dummy variables were created for the categories of where the student currently lived (on/off campus), relationship with parents (good or excellent, all other), number of roommates (zero, one or more), sex of roommates (female, coed/male) and parent's relationship (married, not married). Variables were eliminated from the model using a forward stepwise function. The base model was: Body Image Dissatisfaction $=$ Constant + Resilience +Relationships with Parents + Currently Live + Number of Siblings +Sex of Roommates+ Grade Level + Parent's Relationship

The final model showed a significant f-test of predictive ability of the independent variables $(f=7.69, p<.006)$ and an $r 2$ of .048. While this was limited in power, the model was still highly significant. The regression results indicated that only resilience had a significant 


\section{Internet Scientific Publications}

predictive effect on body image. The standardized coefficients $(-.220, p<.006)$ indicated a .22 unit decrease in body image dissatisfaction as resiliency score increased by one unit. A negative coefficient indicated a negative change in the dependent variable, in this case indicating a smaller difference between ideal and perceived body image. None of the other predictor variables had significant standardized coefficients.

We then re-ran the model using the body image dissatisfaction of where the woman perceived herself to be relative to what she believed a male would ideally like. This model produced a slightly higher $\mathrm{r} 2(.08)$ and similarly significant f-test significance $(p<.000)$. The variable resilience again produced the only significant predictor variable coefficient (-.294, $\mathrm{p}<.000$ ). Consistent with our predictions, a one unit increase in resilience (which was indicated in a one unit increase of the Resilience Scale score) represented a .22 unit decrease in body image dissatisfaction. Given that the average distance of survey respondents between perceived actual and ideal body image was 1.8 image units, reducing this by .22 units with each increase of 1 point on the Resiliency Scale, improves body image satisfaction by $12.2 \%$ on average. This same result was found relative what they thought men would find ideal. For this measure the average body image dissatisfaction was 2.4 image units. But because the regression coefficient was greater (-.294) for this model, the percentage improvement was again $12.2 \%$ for each unit increase in resilience.

\section{Discussion}

Results from this study indicate that there is a significant protective relationship between the level of a woman's resilience and holding a negative body image. These findings are important because they suggest the potential of resilience in limiting body image dissatisfaction in young women. Findings suggest that more resilient persons have less body image dissatisfaction. Given this, differences in mean resiliency scores by subgroups become interesting. Our results indicate that women who feel they have positive relationships with their parents are more resilient (score higher on the resilience scale portion of the survey) than individuals who feel they have poor relationships with their parents. Interpreting the significance of these findings should, however, be interpreted cautiously given that few participants have male roommates or report poor relationships with parents, thus potentially allowing insufficient power to detect significant differences.

Additionally, women also report higher mean resiliency scores if they live with one roommate, but as the number of roommates grows their resiliency declines. This reinforces the findings of Festiger that comparison to a larger reference group motivates women towards uniformity of beliefs about their own ideal body image (7).

\section{Limitations}

There are several limitations to this study. First, data are collected at a single, medium sized, state-based university and may not be generalizable to students at other institutions. It is also conducted using a directed, but not random sample. Given the sampling frame are undergraduate women, a directed judgment sample allows for the best representation within this group. And while using large general education classes represents the five schools and colleges at the university, there still exists the possibility of some sample bias. Second, because students filled out the survey in a classroom setting where the potential exists for respondents to sit next to one another, response bias is a possibility. Women may not have been fully forthcoming with their true beliefs of body image if they felt their responses could be seen. Such a bias would have led to an underestimation of body image dissatisfaction in the sample and thus the magnitude of the protective impact of resiliency. Third, there is an overrepresentation of freshmen 


\section{Internet Scientific Publications}

compared to other classes, and while this is consistent with enrollment at this university, it could have implications of the analysis. For example, freshmen are required to live on campus in same sex housing arrangements. This led to $92 \%$ of the sample reporting they live with other women, and only $8 \%$ living with a male, or in a co-ed environment. We do not anticipate this having an impact on the regression analysis as that variable drops from the regression model. Fourth, is that $93 \%$ of respondents felt they have positive relationships with their parents while only $7 \%$ of respondents felt they have average, poor, or bad relationships with their parents. It is uncertain whether the results would change or vary had the sample sizes for both negative and positive perceived relationships with parents been similar.

\section{Implications}

The need for school counselors to be concerned with body image dissatisfaction in college women has been well documented. Poor body image in adolescent girls can lead to eating disorders such as anorexia and bulimia (33-35) and has been shown to be prominent in college populations and thus is an important clinical concern for college counselors (36). Consequently, many have pointed to the need to identify protective factors when dealing with women with body image dissatisfaction (37). Empirical studies have concluded that counseling and prevention programs should focus on improving physical self concepts, sex role satisfaction, exploring the nature of what is considered thin, improving critical thinking skills, promoting holistic wellness, and enhancing selfesteem $(29,38)$. The practical implication for counselors with respect to clinical practice becomes two-fold. One is in dealing with the immediate effects of holding a poor body image, and the second is in developing treatment strategies to address it, primarily focusing on the promotion of resilience and protective factors. To the former, Cook et al. have suggested utilizing peer educators and mentors, as well as body image therapy, to explore how women view their bodies (38).

With respect to promoting resilience and protective factors, Choate introduced the body image resilience model to provide school counselors with a conceptual framework to address these treatment objectives (29). Although the Choate model has not empirically been tested, this article provides motivation for such an inquiry and supports the model's foundations. The sum of the empirical evidence to date does suggest that by promoting self-esteem and providing protective skills and coping mechanisms, college counselors can enhance the resilience of college women, potentially mitigating body image dissatisfaction.

Future research is still needed to examine the nature of resilience in college age women, its sources and functions. While these findings suggest resilience can have a mitigating effect on negative body image in this population, how that resilience is developed and retained is still unclear.

\section{References}

1. Cash, T. F. \& Pruzinsky, T. (2004). Body image: A handbook of theory, research, and clinical practice. New York: Guilford Press.

2. Hoyt, W. \& Kogan, L.: Satisfaction with Body Image and Peer Relationships for Males and Females in a College Environment. Sex Roles; 2001: 199-215.

3. Ricciardelli, L. A. \& McCabe, M. P.: Children's body image concerns and eating disturbance: A review of the literature. Clinical Psychology Review; 2001: 325-344. 4. Ricciardelli, L. A., McCabe, M. P., Holt, K. E., \& Finnemore, J.: A biopsychosocial model for understanding body image and body change strategies among children. Applied Developmental Psychology; 2003: 475-495.

5. Cooley, E. \& Toray, T.: Body image and personality predictors of eating disorder symptoms during the college years. International Journal of Eating Disorders; 2001a; 30: 28-36. 


\section{Internet Scientific Publications}

6. Parker, S., Michter, M., Vuckovic, N., Sims, C., \& Rittenbaugh, C.: Body and weight concerns among African-American and white adolescent females: Differences that make a difference. Human Organization; 1995; 54: 103-114.

7. Festiger, L.: A theory of social comparison processes. Human Relations; 1954: 114140.

8. Engeln-Maddox, R.: Cognitive responses to idealized media images of women: the relationship of social comparison and critical processing to body image disturbance in college women. Journal of Social and Clinical Psychology; 2005; 24: 1114-1138.

9. Byerly, L., Archibald, A., Graber, J., \& Brooks-Gunn, J.: A prospective study of familial and social influences on girls' body image and dieting. International Journal of Eating Disorders; 2000; 28: 155-164.

10. Buss, D. M. (1994). The evolution of desire: Strategies of human mating. New York: Basic Books.

11. Feingold, A.: Good looking people are not what we think. Psychological Bulletin; 1992; 111: 304-344.

12. Jackson, L. A. (1992). Physical appearance and gender: Sociobiological and sociocultural perspectives. Albany: State University of New York Press.

13. Lundy, D. E., Tan, J., \& Cunningham, M. R.: Heterosexual romantic preferences: The importance of humor and physical attractiveness for different types of relationships. Personal Relationships; 1998; 5: 311-325.

14. Townsend, J. M. \& Levy, G. D.: Effects of potential partners' costume and physical attractiveness on sexuality and partner selection. Journal of Psychology; 1998; 124: 371389.

15. Graber, J., Brooks-Gunn, J., Paikoff, R. L., \& Warren, M. P.: Prediction of eating problems: An 8-year study of adolescent girls. Developmental Psychology; 1994; 30: 823834.

16. Stormer, S. M. \& Thompson, J. K.: Explanations of body image disturbance: A test of maturational status, negative verbal commentary, social comparison, and sociocultural hypotheses. International Journal of Eating Disorders; 1996; 19: 193-202.

17. Taylor, C. B., Sharpe, T., Shisslak, C., Bryson, S., Estes, L. S., Gray, N. et al.: Factors associated with weight concerns in adolescent girls. International Journal of Eating Disorders; 1998; 24: 31-42.

18. Garner, D. M., Garfinkel, P. E., Schwartz, D., \& Thompson, M.: Cultural expectations of thinness in women. Psychological Reports; 1992; 47: 83-91.

19. Wiseman, C. V., Gray, J. J., Mosimann, J. E., \& Ahrens, A. H.: Cultural expectations of thinness in women: An update. International Journal of Eating Disorders; 1992; 11: 8589.

20. Anderson, A. E. \& Dimenico, D.: Diet vs. shape content of popular male and female magazines: A dose-response relationship to the incidence of eating disorders? International Journal of Eating Disorders; 1992; 11: 283-287.

21. Thompson, J. K., Heinberg, L. J., Altabe, M., \& Tantleff-Dunn, S. (1999). Exacting beauty: Theory, assessment, and treatment of body image disturbance. Washington, D.C.: American Psychological Association.

22. Hesse-Biber, S., Marino, M., \& Watts-Roy, D.: A longitudinal study of eating disorders among college women: Factors that influence recovery. Sociologists for Women in Society; 1999; 13: 385-408.

23. Wiederman, M. W. \& Hurst, S. R.: Physical attractiveness, body image, and women's sexual self-schema. Psychology of Women Quarterly; 1997; 21: 567-580.

24. Forbes, G., Jobe, R., \& Richardson, R.: Associations between having a boyfriend and the body satisfaction and self-esteem of college women: An extension of the Lin and Kulik hypothesis. The Journal of Social Psychology; 2006; 146: 381-384.

25. Hyde, J., Mezulis, A., \& Abramson, L. The ABCs of depression: Integrating affective, biological, and cognitive models to explain the emergence of the gender difference in depression. Psychology Review; 2008; 115: 2.

26. Rubin, L., Nemeroff, C., \& Russo, N.: Exploring feminist women's body consciousness. Psychology of Women Quarterly; 2004; 28: 27-37.

27. Ahrens, A. H., Kieh, E., Sole, M., \& Byers, J.: A review of instruments measuring resilience. Issues in Comprehensive Pediatric Nursing; 2006; 29: 103-125.

28. Choate, L.: Toward a theoretical model of women's body image resilience. Journal of Counseling and Development; 2005; 83: 320-330.

29. Choate, L.: Counseling adolescent girls for body image resilience: Strategies for school counselors. Professional School Counseling; 2007; 10: 317-330.

30. Cooley, E. \& Toray, T.: Disordered eating in college freshmen women: A prospective study. Journal of American College Health; 2001b; 49: 229-235.

31. Peterson, M., Ellenberg, D., \& Crossman, S.: Body image perceptions: Reliability of a BMI-based silhouette matching test. American Journal of Health Behaviors; 2003; 27 : 355-363.

32. Wagnlid, G. M. \& Young, H. M. Development and psychometric evaluation of the resilience scale. Journal of Nursing Measurement; 1993; 1: 165-178.

33. Kostanski, M. \& Gullone, E.: Adolescent body image dissatisfaction: Relationships with self-esteem, anxiety, and depression controlling for body mass. Journal of Child Psychology and Psychiatry; 1998; 39: 255-262.

34. Levine, M. P. \& Smolak, L. (2002). Body image development in adolescence. In Body Image: A handbook of theory, research and clinical practice (pp. 74-82). New York: Guilford.

35. Polivy, J. \& Herman, C. P.: The effects of resolving diet on restrained and unrestrained eaters: The "false hopes" syndrome. International Journal of Eating Disorders; 1999; 26: 434-447.

36. Ferrier, A., Martens, M., \& Cimini, M. D.: The relationship between physical, sexual, and emotional abuse and unhealthy weight loss behaviors. Journal of College 


\section{Internet Scientific Publications}

Counseling; 2005; 6: 80-89.

37. James, K. A., Phelps, L., \& Bross, L.: Body dissatisfaction, drive for thinness, and self-esteem in African American college females. Psychology in the Schools; 2001; 38: 491-496.

38. Cook-Cottone, C. \& Phelps, L.: Body image dissatisfaction in college women: Identification of risk and protective factors to guide college counseling practices. Journal of College Counseling; 2003; 6: 80-89.

- \{full_citation\} 